\title{
Total electron content variations over southern Europe before and during the M 6.3 Abruzzo earthquake of April 6, 2009
}

\author{
Michael E. Contadakis ${ }^{1}$, Dimitrios N. Arabelos ${ }^{1}$, Christos Pikridas ${ }^{1}$, Spyrous D. Spatalas ${ }^{1}$
}

${ }^{1}$ Aristotle University of Thessaloniki, Department of Geodesy and Surveying, Thessaloniki, Greece

Article history

Received July 21, 2011; accepted January 12, 2012.

Subject classification:

Seismic Risk, GPS network, Ionospheric total electron content, Wavelet analysis.

\section{ABSTRACT}

Total electron content (TEC) data of 14 global positioning system (GPS) stations of the EUREF network were provided by the IONOLAB. These were analyzed using wavelet analysis and discrete Fourier analysis to investigate the TEC variations over southern Europe in the month before the catastrophic Abruzzo earthquake of M 6.3 of April 6, 2009. The main conclusions of this analysis are: (a) TEC oscillations in a broad range of frequencies occurred randomly over a broad area of several hundred kilometers from the earthquake; (b) Morning and evening extensions of the day-time TEC values were seen for all of the EUREF stations of this program shortly before, during and shortly after the main earthquake period; (c) High frequency oscillations ( $f \geq 0.0003 \mathrm{~Hz}$, period $\mathrm{T} \geq 60 \mathrm{~m}$ ) appear to indicate the location of the earthquake, although with questionable accuracy, while the fractal characteristics of the frequency distribution indicates the locus of the earthquake with relatively greater accuracy. We conclude that the lithosphere-atmosphere-ionosphere coupling mechanism through acoustic or gravity waves might explain this phenomenology.

\section{Introduction}

It is generally accepted by the scientific community that the tectonic activity that results in earthquakes can induce variations in the Earth ionosphere through the socalled lithosphere-atmosphere-ionosphere coupling (LAIC) mechanism [Molchanov et al. 2004, Molchanov and Hayakawa 2008, Korepanov et al. 2009]. This strong opinion has emerged from the data from a large number of studies carried out that have been ground-based [Molchanov et al. 2004, 2005, Liperovsky et al. 2002, Svets et al. 2004, Rozhnoi et al. 2004, 2009, Biagi et al. 2009, Hayakawa et al. 2011], space-born [Parrot 2006, Hayakawa et al. 2000], or combined ground-based and space-born [Rozhnoi et al. 2007, Muto et al. 2008]. The development of the global positioning system (GPS) and the Global Navigation Satellite System has also provided perfect opportunities for simultaneous inspection of total electron content (TEC) variations over a great number of locations around the Earth. A lot of studies have also been carried out using these to investigate the interrelationships of these TEC variations, or to isolate variations in TEC data that might occur over particular sites with enhanced tectonic activity [see, for instance, Afraimovich et al. 2001, 2002, Contadakis et al. 2008]. These studies have indicated that in a broader area over a site where a strong earthquake occurs (magnitude $>5.5$ ), uneven variations in TEC are observed. Therefore, the Abruzzo earthquake of M 6.3 of April 6, 2009, provided an occasion of great interest to look for any significant characteristics that can potentially be used in earthquake forecasting.

In the present study, TEC data of 14 GPS stations of the International Association of Geodesy Reference Frame Sub-Commission for Europe (EUREF) network (http:/ / www.epncb.oma.be) that were provided by the Ionospheric Research Laboratory (IONOLAB, Turkey) (http://www.ionolab.org) were analyzed using wavelet analysis and discrete Fourier analysis, to investigate TEC variations over southern Europe in the month prior to this catastrophic Abruzzo earthquake of April 6, 2009.

\section{The data}

\subsection{TEC data and Dst index}

In the present study, we were interested in the variations in TEC over a broad area around the catastrophic Abruzzo earthquake, so we used TEC estimates provided by IONOLAB (http:/ / www.ionolab.org) [Arikan et al. 2009] for the GPS stations of EUREF, which cover the south of Europe, for the time period between March 11, 2009, and April 9, 2009. Unfortunately, TEC data for the stations of EUREF of central Italy were not available. However, TEC data over Rome (Italy) were kindly provided to us by Dr. Ciraolo [personal communication, 2009]. Table 1 gives the locations of the 14 EUREF stations. The IONOLAB TEC estimation system uses a single station receiver bias estimation algorithm, IONOLAB-BIAS, to obtain the daily 
and monthly averages of receiver bias, which is successfully applied to both quiet and disturbed days of the ionosphere for station positions at any latitude. In addition, TEC estimations with high resolution are possible [Arikan et al. 2008]. The IONOLAB system provides comparisons on its site of their TEC estimations with those of the other TEC providers of the International Navigation Satellite System Service. In the present study, only TEC estimations that were in perfect agreement across all of these providers were used. TEC values are provided in the form of a time series with a sampling gap (resolution) of $2.5 \mathrm{~min}$. However, in time periods of uneven variations of TEC, the provider changes the sampling resolution to $2.0 \mathrm{~min}$ or $1.0 \mathrm{~min}$, or even to 0.5 min, in an unpredictable way, which makes the fast Fourier transform (FFT) elaboration of the time series more difficult. Therefore, special attention was paid to the analysis of segments of data with the same sampling gap. This was not necessary in the case of wavelet analysis. Figure 1 shows the variations of TEC over these 14 EUREF stations during the time period of March 11, 2009, to April 9, 2009.

The variations in the geomagnetic field were followed according to the Dst index quoted on the site of the Space Magnetism Faculty of Science, Kyoto University (Japan) (http://swdcwww.kugi.kyoto-u.ac.jp/index.html) for the time period of our data. Figure 2 shows these Dst index variations for March 2009. It can be seen that in general, the geomagnetic field was relatively quiet in March 2009, with some slight variations on March 13 (-30 nT), 21 (-27 $\mathrm{nT})$ and $24(-24 \mathrm{nT})$. The geomagnetic field remained quiet until April 9, 2009 (data not shown, for space considerations).

\begin{tabular}{cccccc}
\hline No GPS station Epicentral Longitude & $\begin{array}{c}\text { Latitude } \\
\text { distance } \\
(\mathrm{km})\end{array}$ & Location \\
\hline 1 & YEBES & 1400.8 & -3.0886 & 40.5200 & Yebes (Spain) \\
2 & LRC & 1193.8 & -1.2193 & 46.1589 & LaRochelle (France) \\
3 & TLSE & 961.0 & 1.4812 & 43.5607 & Toulouse (France) \\
4 & MARS & 650.6 & 5.3538 & 43.2788 & Marseille (France) \\
5 & AJAC & 379.0 & 8.7626 & 41.9275 & Ajaccio (France) \\
6 & GEN & 413.7 & 8.9211 & 44.4144 & Genova (Italy) \\
7 & CAGL & 520.6 & 8.9728 & 39.1359 & Ajaccio (France) \\
8 & ROM & 87.8 & 12.4900 & 41.8900 & Rome (Italy) \\
9 & NOT1 & 632.4 & 14.9898 & 36.8759 & Noto (Italy) \\
10 & MATE & 347.0 & 16.7045 & 40.6491 & Matera (Italy) \\
11 & OHRI & 644.4 & 20.8019 & 41.1172 & Ohrid (FYROM ${ }^{\star}$ ) \\
12 & SOFI & 827.0 & 23.3947 & 42.5561 & Sofia (Bulgaria) \\
13 & BUCU & 1043.4 & 26.1257 & 44.4639 & Bucharest (Romania) \\
14 & ANKR & 1683.6 & 32.7586 & 39.8875 & Ankara (Turkey) \\
\hline
\end{tabular}

^ FYROM, former Yugoslav Republic of Macedonia

Table 1. The EUREF stations of southern Europe.

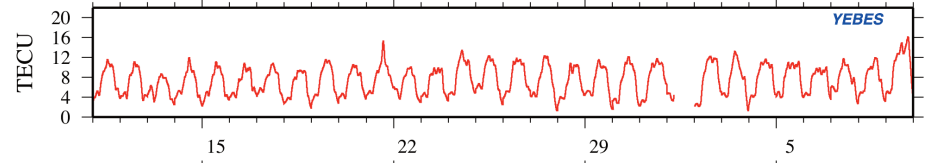

$\underbrace{}_{15}$

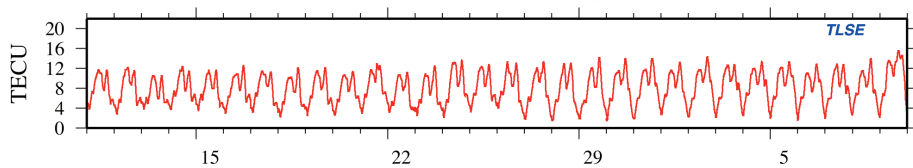

MARS

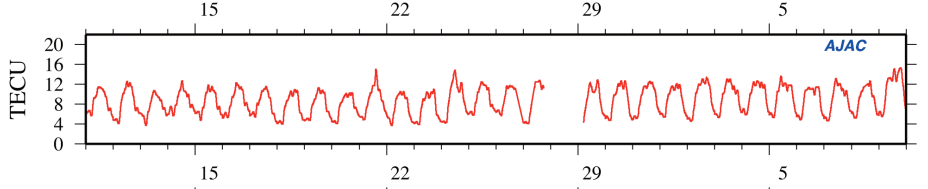

$\underbrace{20}_{15}$

$\underbrace{}_{15}$

$\underbrace{}_{15}$

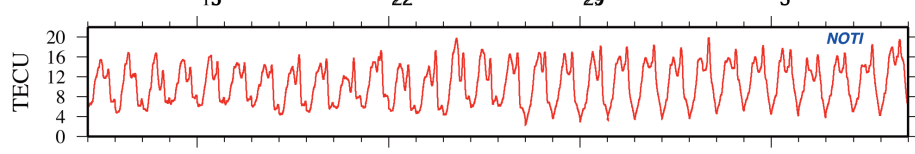

年

$\underbrace{20}_{15}$

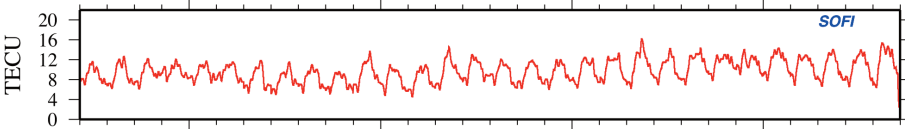

$15 \quad{ }_{22} \quad{ }_{29} \quad{ }_{5}$

兽 $\begin{gathered}20 \\ 112 \\ 4 \\ 0\end{gathered}$

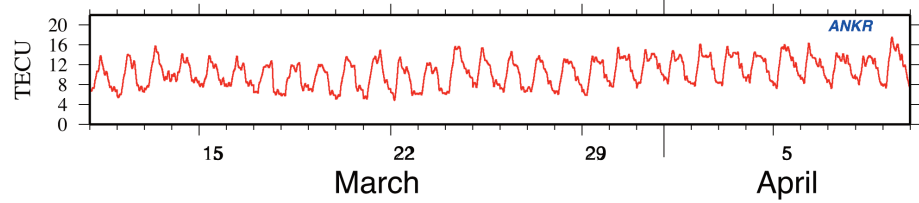

Figure 1. TEC variations for the time period between March 11, 2009, and April 9, 2009, for the EUREF stations. 


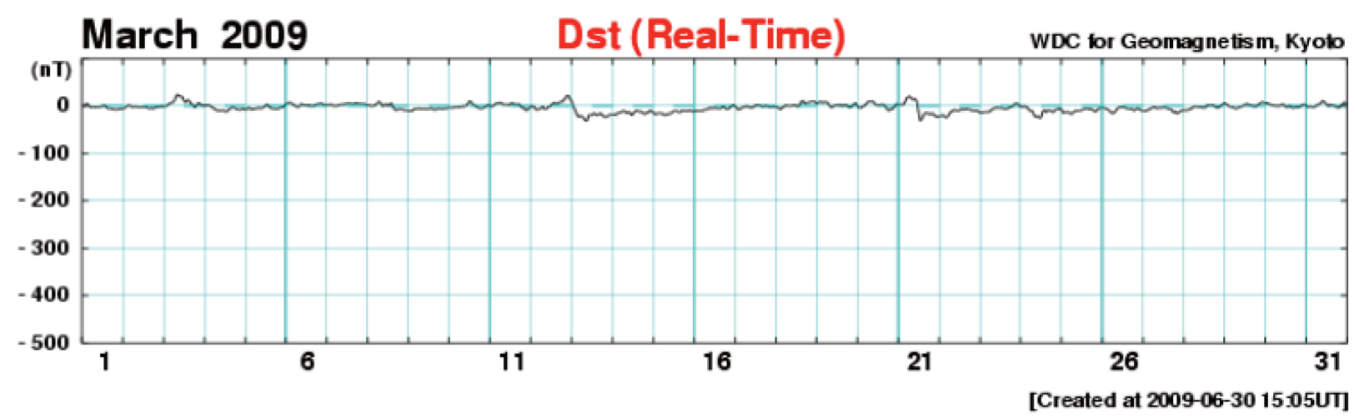

Figure 2. Dst variations in March, 2009

\begin{tabular}{|c|c|c|c|c|c|c|}
\hline $\begin{array}{c}\text { Date } \\
\text { (yyyy-mm-dd) }\end{array}$ & $\begin{array}{c}\text { Time } \\
\text { (hh:mm:ss) }\end{array}$ & M & $\begin{array}{l}\text { Lat. } \\
\left({ }^{\circ}\right)\end{array}$ & $\begin{array}{l}\text { Lon. } \\
\left({ }^{\circ}\right)\end{array}$ & $\begin{array}{l}\text { Depth } \\
(\mathrm{km})\end{array}$ & Description \\
\hline 2009-06-22 & $20: 58: 40$ & 4.7 & 42.5 & 13.4 & 2.0 & Central Italy \\
\hline 2009-06-21 & 11:20:04 & 4.6 & 43.5 & 17.3 & 10.0 & Northwestern Balkan Peninsula \\
\hline 2009-06-07 & 09:00:06 & 4.7 & 38.3 & 22.1 & 2.0 & Greece \\
\hline 2009-06-01 & 08:03:39 & 4.5 & 41.2 & 22.7 & 2.0 & Northwestern Balkan Peninsula \\
\hline 2009-05-30 & $02: 55: 25$ & 4.8 & 43.3 & 13.2 & 60.0 & Central Italy \\
\hline $2009-05-28$ & $08: 43: 33$ & 4.6 & 41.2 & 20.2 & 2.0 & Albania \\
\hline $2009-05-24$ & $19: 37: 05$ & 5.0 & 41.3 & 22.7 & 2.0 & Northwestern Balkan Peninsula \\
\hline 2009-05-24 & 16:23:09 & 4.6 & 41.3 & 22.7 & 2.0 & Northwestern Balkan Peninsula \\
\hline $2009-05-24$ & $16: 17: 50$ & 5.4 & 41.3 & 22.7 & 2.0 & Northwestern Balkan Peninsula \\
\hline $2009-05-17$ & $22: 39: 26$ & 4.5 & 38.1 & 22.7 & 2.0 & Greece \\
\hline 2009-05-17 & 11:59:04 & 4.7 & 38.1 & 22.8 & 10.0 & Greece \\
\hline 2009-05-02 & $15: 44: 20$ & 4.5 & 37.6 & 22.8 & 60.0 & Southern Greece \\
\hline 2009-04-13 & $21: 14: 25$ & 5.1 & 42.5 & 13.3 & 2.0 & Central Italy \\
\hline 2009-04-10 & $03: 22: 23$ & 5.2 & 42.6 & 13.5 & 5.0 & Central Italy \\
\hline 2009-04-09 & $19: 38: 17$ & 5.2 & 42.5 & 13.3 & 2.0 & Central Italy \\
\hline 2009-04-09 & 00:53:00 & 5.2 & 42.5 & 13.4 & 2.0 & Central Italy \\
\hline 2009-04-07 & $21: 34: 30$ & 4.5 & 42.3 & 13.4 & 2.0 & Central Italy \\
\hline 2009-04-07 & $17: 47: 37$ & 5.5 & 42.3 & 13.5 & 2.0 & Central Italy \\
\hline 2009-04-07 & 09:26:30 & 5.0 & 42.3 & 13.3 & 10.0 & Central Italy \\
\hline 2009-04-06 & $23: 15: 37$ & 5.1 & 42.5 & 13.4 & 2.0 & Central Italy \\
\hline 2009-04-06 & $03: 56: 48$ & 4.5 & 42.4 & 13.3 & 10.0 & Central Italy \\
\hline 2009-04-06 & 02:37:05 & 5.1 & 42.4 & 13.3 & 2.0 & Central Italy \\
\hline 2009-04-06 & $01: 32: 41$ & 6.2 & 42.4 & 13.3 & 2.0 & Central Italy \\
\hline 2009-02-20 & $21: 10: 10$ & 4.5 & 39.4 & 20.2 & 2.0 & Greece-Albania border region \\
\hline $2009-02-16$ & $23: 16: 39$ & 5.3 & 37.4 & 20.7 & 10.0 & Ionian Sea \\
\hline 2009-02-02 & $04: 13: 35$ & 4.7 & 37.6 & 20.9 & 50.0 & Ionian Sea \\
\hline 2009-02-01 & 00:57:08 & 4.8 & 38.5 & 20.3 & 20.0 & Greece \\
\hline 2009-01-08 & 12:04:04 & 5.0 & 41.8 & 20.9 & 2.0 & Albania \\
\hline
\end{tabular}

Table 2. Seismic activity in a broader area of central Italy (events within $5^{\circ}$ distance from the selected latitude of $40.97^{\circ} \mathrm{N}$ and longitude of $18.21^{\circ} \mathrm{E}$ ).

2.2. Seismic activity of central Italy and over the broader area As we were studying TEC variations over southern Europe, we here considered the seismic activity over a broader area of central Italy (within $5^{\circ}$ from the selected point with latitude $40.97^{\circ} \mathrm{N}$ and longitude $18.21^{\circ} \mathrm{E}$ ). Table 2 gives the seismic activity in this broader area of central Italy, as cited from the website of Orfeus Wilbert II, http:/ / www.orfeuseu.org/cgi-bin/wilberII/wilberII_page2.pl.

It can be seen that apart from the seismic activity in central Italy that was associated with the main event of the Abruzzo earthquake of April 6, 2009, which has been thoroughly studied [Atzori et al. 2009, Cirella et al. 2009], 
there was weak seismic activity in the Ionian Sea and in Albania that started before, and developing in parallel with, the central Italy activity. There was also seismic activity in the northwestern Balkan peninsula that started one month later (Table 2).

\section{The data analysis}

The data consist of TEC values sampled every $2.5 \mathrm{~min}$ for each station for the time interval between March 11, 2009, and April 9, 2009. To determine any particular variations in TEC over the broader area of the Abruzzo earthquake that might have been connected with the related tectonic activity, we first compared the variations over all of the EUREF stations for this time period. We then analyzed the data time series using both wavelet analysis and FFT analysis, for a more detailed investigation. As mentioned above, in periods of uneven TEC variations, the provider abruptly changes the resolution to every $2.0,1.0$ or $0.5 \mathrm{~min}$. These alterations can be easily compensated for in wavelet analysis by considering the local frequency alterations, although in the FFT analysis, special attention was taken to analyze segments at the same resolution.

Wavelet analysis provides a powerful tool in the investigation of weak transient oscillations in the timefrequency domain, and therefore it is very useful in problems of geophysics where such oscillatory behavior is investigated [see for example, Alperovich et al. 2003]. The basic idea is the correlation of a given wavelet form with the variation in the observational data series. There are several options for the analysis of time series. In this analysis, we used onedimensional discrete wavelet analysis to keep an eye on the frequency alterations due to the changes in the resolution of the data. We used the Biorthogonal 6.8 wavelet. This is a compactly supported wavelet for which symmetry and exact reconstruction are possible, and it can be used for discrete as well as continuous wavelet analysis. Figure 3 shows the characteristics of wavelet Biorthogonal 6.8 [Misiti et al. 1996]. We chose this wavelet because it is symmetric and sharp cutting, something that intuitively we expected would be suitable for this analysis of TEC variations.

\section{Results and discussion}

\subsection{The overall variation in TEC}

The variations in TEC over the 14 EUREF stations for the time period from March 11, 2009, to April 9, 2009, are shown in Figure 1. Inspecting these daily TEC variations for each station, we can define some differences from their comparisons. The night-time TEC values of March 13 are higher than those of the adjacent days, by 1 to 4 TECU, for all of the stations except for three (YEBE, LRC and TLS). The day-time TEC values of March 21 are higher than those of the adjacent days by 1 to 4 TECU, for all of the stations apart from GEN. Finally, the day-time and night-time TEC values of March 24 are higher than those of the adjacent days by 1 to 4 TECU for all of the stations apart from GEN. These differences might be explained as a result of the short variations in the geomagnetic field on the respective days.

According to Afraimovich et al. [2000], the increase in the level of geomagnetic activity is accompanied by an increase in the total intensity of TECs, which correlates with the gradient of the Dst, but not with the absolute levels of the Dst.

Next, we realized that for the time period from March 29, 2009, to April 9, 2009, day-time TEC values were
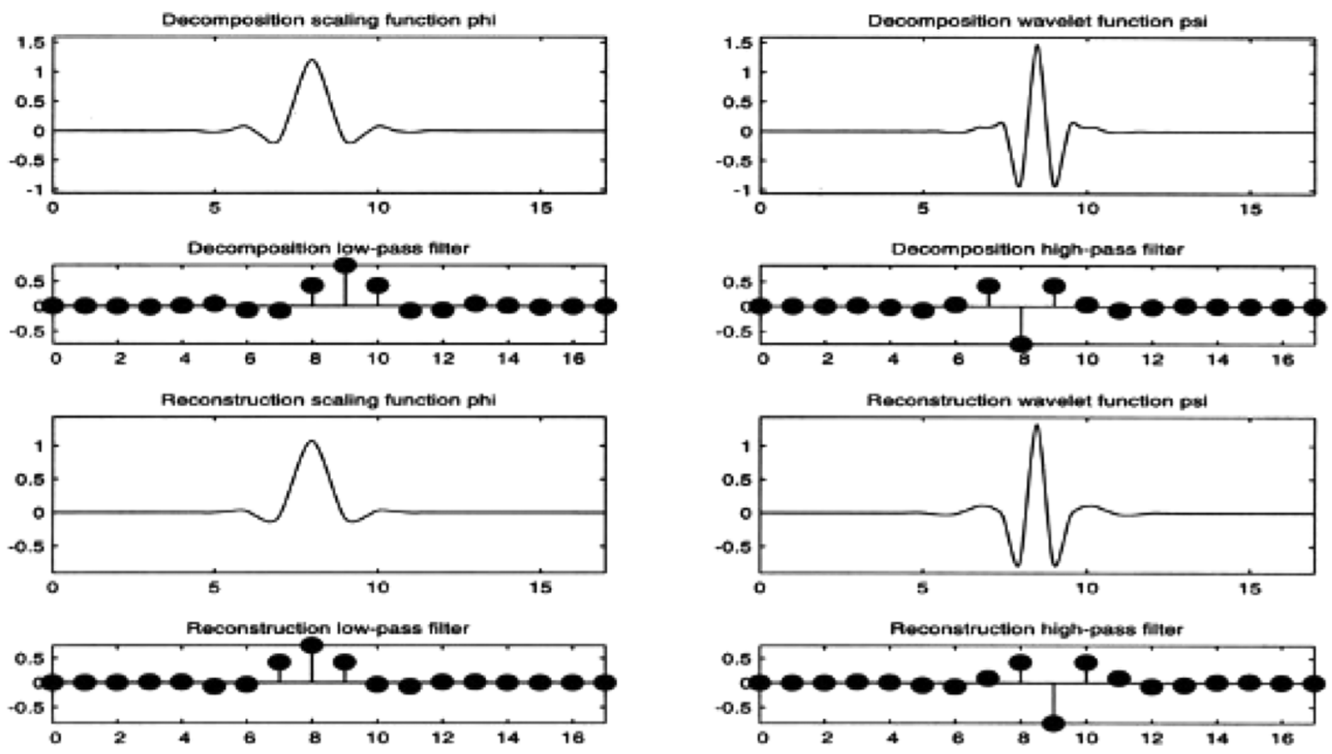

Figure 3. Characteristics of wavelet Biorthogonal 6.8. Upper panels: The decomposition, showing scaling function phi (upper left), wavelet function psi (upper right), and the low-pass (lower left) and high-pass (lower right) filters. Lower panels: the reconstruction, as for the decomposition. 


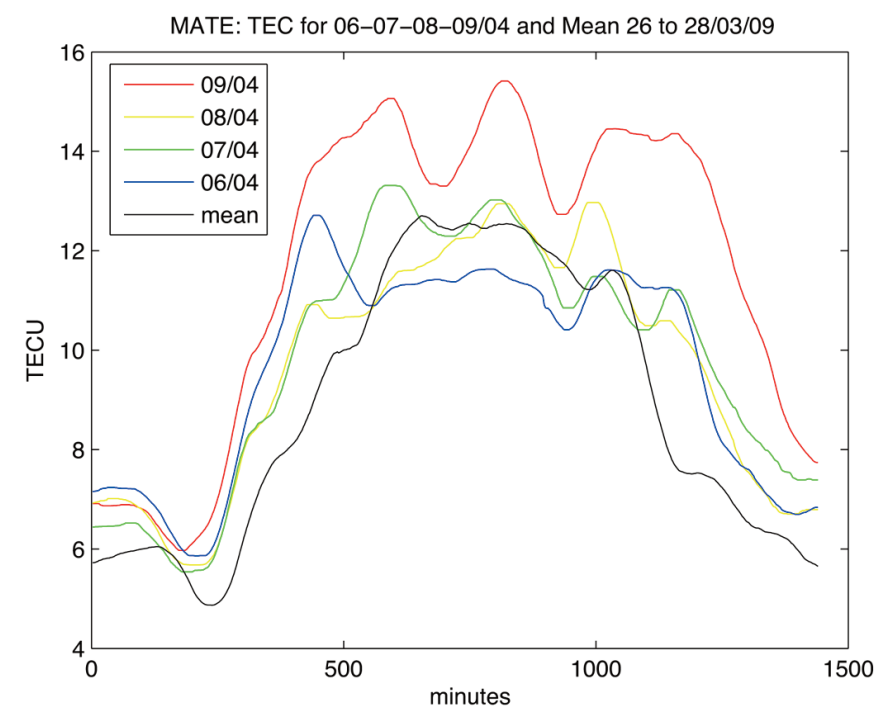

Figure 4. TEC for April 6 to 9, 2009, and mean TEC for March 26 to 28, 2009, over the MATE station.

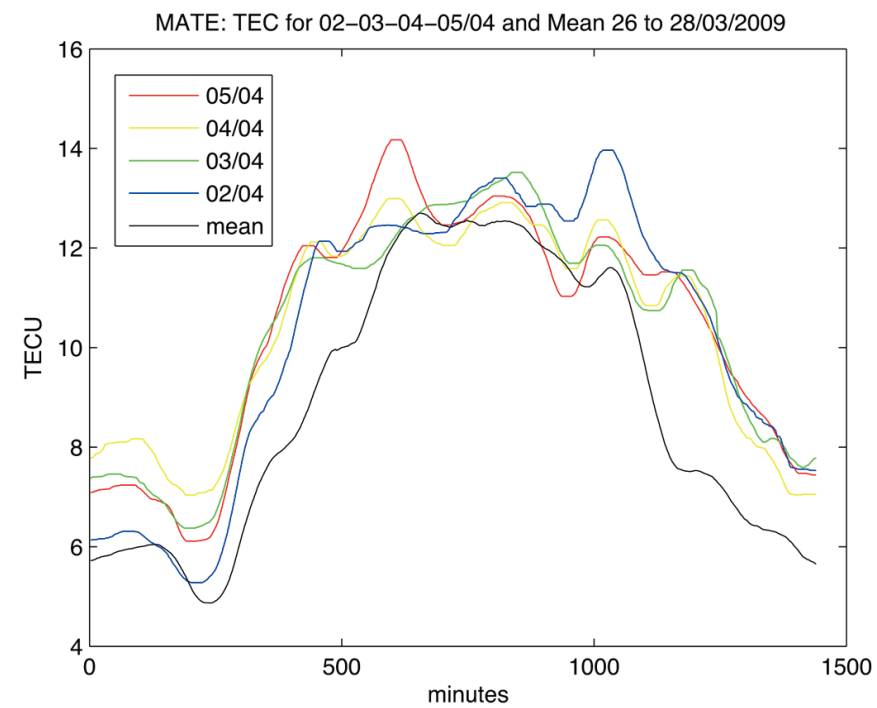

Figure 5. TEC for April 2 to 5, 2009, and mean TEC for March 26 to 28, 2009, over the MATE station. morning and evening extended by $30 \mathrm{~min}$ to $250 \mathrm{~min}$ for all of the stations, compared with the mean day-time TEC durations for each station. Figures 4, 5 and 6 show these morning and evening extensions for the MATE station, and Figure 7 shows these daily TEC extensions over all of the stations for the day of April 4, 2009, as an example.

As there were no great geomagnetic disturbances during the time period of March 29, 2009, to April 9, 2009, which in addition was a period of minimal solar cycle and flare activity, we can conclude that the observed TEC variations over the GPS stations are connected with the tectonic activity of the broader area of the Italian and Balkan peninsulas that occurred during this time period. More specifically, we suggest that lithospheric perturbations transmitted through a LAIC mechanism in the ionosphere influenced the turbidity and ionization of all of the

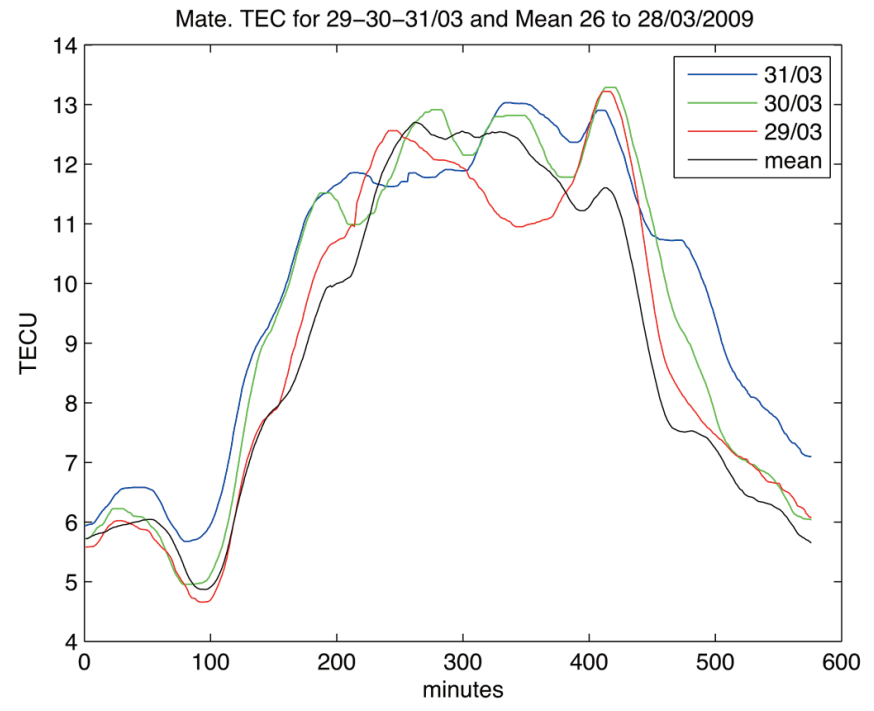

Figure 6. TEC for March 29 to 31 and April 1, 2009, and mean TEC for March 26 to 28, 2009, over the MATE station.

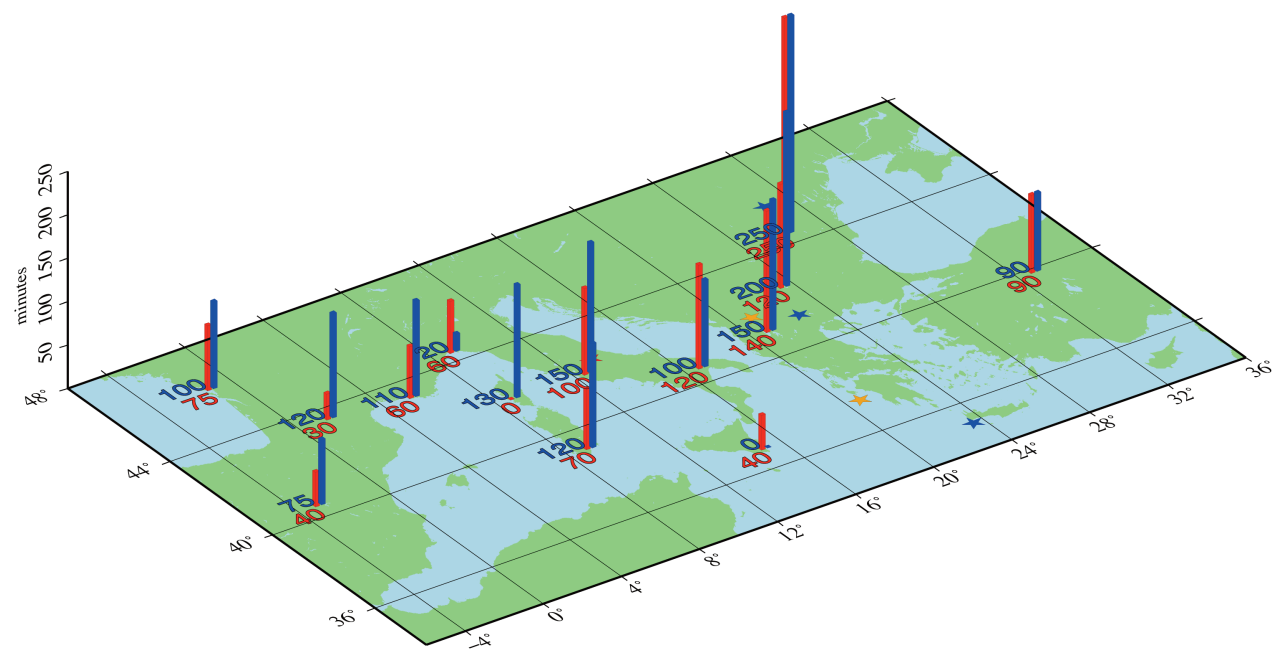

Figure 7. Morning (red) and evening (blue) extensions of day-time TEC values over the stations of the network on April 4, 2009. 
ionospheric layers, and might generate the spread E (Es) layer phenomena too. According to Liperovski et al. [2005], thermal, pressure and ionic variations generated at ground level as a result of tectonic stress in the preparation period for an earthquake can propagate upwards through the atmosphere as acoustic or standing gravity waves, and can
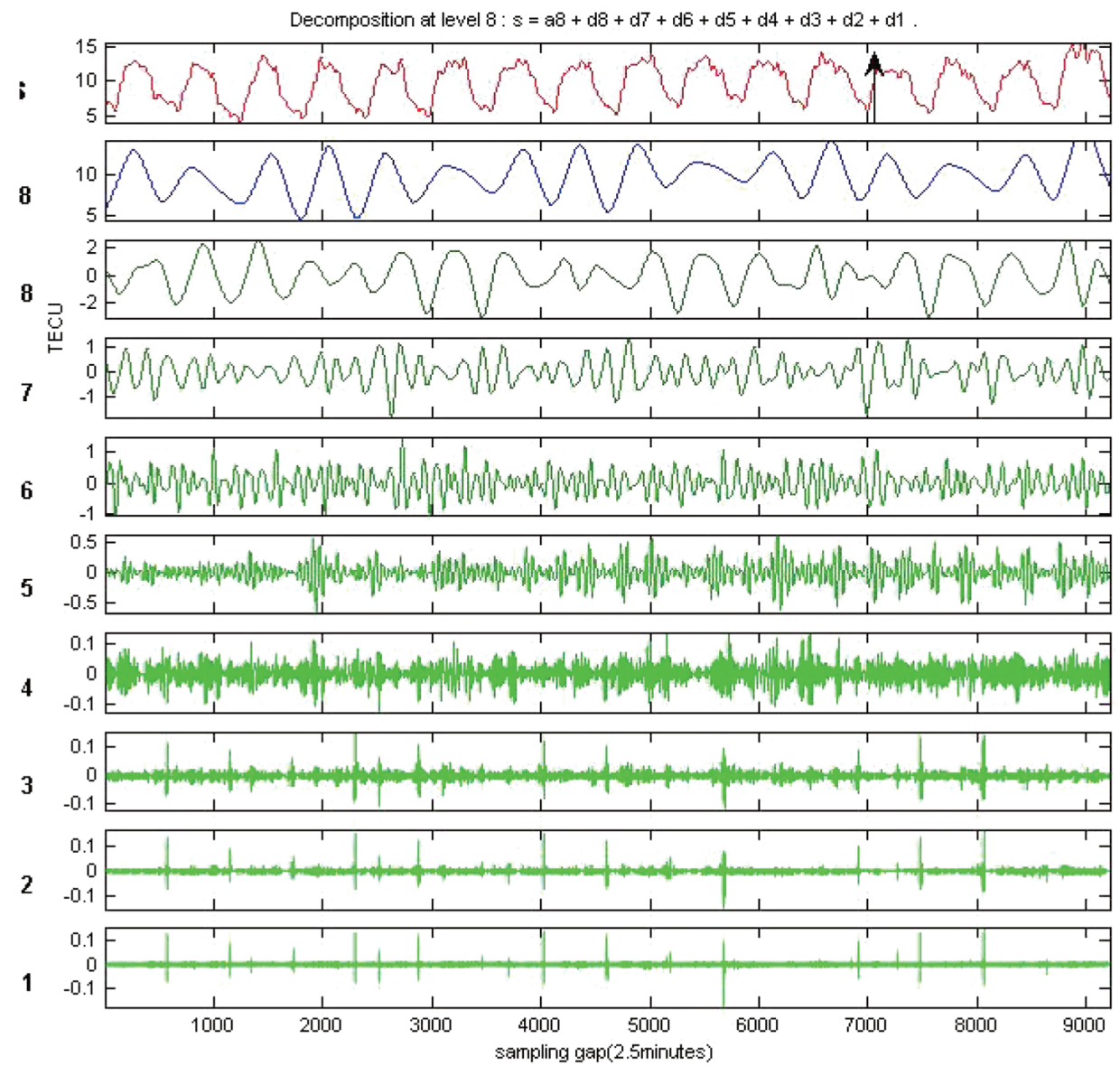

Figure 8. TEC variations over the MATE station in TECU, and variations of the components with periods of $5 \mathrm{~min}(1), 10 \mathrm{~min}(2), 20 \mathrm{~min}(3), 40 \mathrm{~min}(4)$, $80 \mathrm{~min}$ (5), $160 \mathrm{~min}$ (6), $320 \mathrm{~min}$ (7), and $640 \mathrm{~min}$ (8) for the time period of March 25, 2009, to April 9, 2009. Arrow, main shock of the L'Aquila earthquake of M 6.3 on April 6, 2009.

\begin{tabular}{|c|c|c|c|c|c|c|c|c|}
\hline \multirow[b]{2}{*}{ No } & \multirow[b]{2}{*}{ Station } & \multicolumn{7}{|c|}{ Period (min) } \\
\hline & & 10 & 20 & 40 & 80 & 160 & 320 & 640 \\
\hline 1 & YEBES & 0.2646 & 0.2214 & 1.1480 & 1.4560 & 3.7080 & 5.7620 & 6.5370 \\
\hline 2 & LRC & 0.3194 & 0.3249 & 0.7956 & 1.2140 & 2.8750 & 3.2950 & 5.6440 \\
\hline 3 & TLS & 0.4939 & 0.4395 & 1.0330 & 1.5450 & 4.7110 & 7.2910 & 7.7770 \\
\hline 4 & MARS & 0.1321 & 0.1131 & 0.2000 & 1.0000 & 1.9000 & 3.0000 & 5.0000 \\
\hline 5 & AJAC & 0.3180 & 0.3180 & 0.3000 & 1.2000 & 3.0000 & 2.5000 & 6.3320 \\
\hline 6 & GEN & 0.4575 & 0.3230 & 1.4170 & 2.0310 & 5.3350 & 7.4920 & 9.0570 \\
\hline 7 & CAGL & 0.7554 & 0.6936 & 1.7210 & 1.8180 & 1.9990 & 4.2000 & 3.9840 \\
\hline 8 & ROM & 0.2968 & 0.3090 & 0.8110 & 0.7483 & 0.8027 & 1.9640 & 3.2410 \\
\hline 9 & NOT & 0.6779 & 0.6375 & 0.6718 & 1.7980 & 6.8590 & 8.8680 & 10.2300 \\
\hline 10 & MATE & 0.4145 & 0.6023 & 0.4022 & 1.4420 & 2.8240 & 3.8120 & 6.2920 \\
\hline 11 & OHRI & 0.3426 & 0.3208 & 0.5680 & 1.3600 & 2.5790 & 3.2260 & 1.1880 \\
\hline 12 & SOFI & 0.3544 & 0.3165 & 0.8320 & 1.1690 & 2.4480 & 3.3290 & 5.2050 \\
\hline 13 & BUCU & 0.6215 & 0.6622 & 0.3945 & 1.4120 & 2.4240 & 3.2000 & 5.2780 \\
\hline 14 & ANKR & 0.4301 & 0.4015 & 0.4000 & 1.1000 & 2.6000 & 3.5000 & 6.5000 \\
\hline
\end{tabular}

Table 3. The range of the variations of the constituents with the periods ranging from 10 min to 640 min in the time interval from April 4 to 6,2009 . 
thus produce modifications of the turbulization of the Es layers. It should be noted that Lisi et al. [2010] and Pergola et al. [2010] reported the occurrence of ground thermal anomalies in the time period of March 15, 2009, to April 15, 2009 , in areas of north Italy, Sicily, the Mediterranean Sea, south Adriatica and the Balkan peninsula.

The increase in the electronic content of the lower ionosphere is observed as morning or evening extensions of TEC values during each day for the time period of March 29, 2009, to April 9, 2009. In addition, the increase in the electronic content of the $\mathrm{D}$ and $\mathrm{E}$ ionospheric layers altered the waveguide of the very low frequency (VLF)/low frequency (LF) radio propagation, and generated destructive interference of ground and sky waves [e.g., Hayakawa 2007]. As a result, the strength of the signal drops. In the course of the daily TEC variation, this happened in the morning and the evening, and the moment of this destructive interference is known as the terminator time. It is well known that a shift in the terminator time can be observed several days before an earthquake. Yoshida et al. [2008] demonstrated that this terminator time shift results from increased electronic content of the lower ionosphere for several days around the occurrence of a strong earthquake. Therefore, our results are in agreement with those of Rozhnoi et al. [2009], who reported an anomalous evening terminator time in the time interval of 2-8 days before the L'Aquila earthquake.

\subsection{Wavelet analysis}

Figure 8 shows an example of the wavelet analysis, as the variations in TEC over the GPS station MATE. This covers the time period of before, during and after the main shock of the L'Aquila earthquake; i.e. from March 25, 2009, to April 9, 2009 (Figure 8, red). Figure 8 also shows the variations in the components with periods of $5 \mathrm{~min}, 10 \mathrm{~min}$, $20 \mathrm{~min}, 40 \mathrm{~min}, 80 \mathrm{~min}, 160 \mathrm{~min}, 320 \mathrm{~min}$ and $640 \mathrm{~min}$. The moment of the main shock is marked on the figure by a black arrow. The axes of Figure 8 give the TECU (Y axis: 1 TECU $=10^{16}$ electrons $\mathrm{m}^{-2}$ ) and the sampling gap (resolution; $\mathrm{X}$ axis: $2.5 \mathrm{~min}$ ).

In Figure 8, the top panel (red) shows the variations in TEC, the second panel (blue) shows the remaining variations in TEC after the subtraction of the eight variations (below; green) as noise. This residual apparently includes tidal variations, with longer wavelengths than those that were subtracted. Finally, these next eight diagrams (Figure 8, green) show the variations in the eight components. Table 3 gives an overview of the results of this analysis; namely, the range of the variations in all eight of the components over the EUREF stations for the days of April 4, 5 and 6, 2009; i.e. just before the main shock, and on the day of the main shock.

These results indicate that around the day of the main shock, there are high frequency components (frequencies ranging between $0.003 \mathrm{~Hz}$ - period, $5 \mathrm{~min}-$ and $0.0002 \mathrm{~Hz}-$ period, $100 \mathrm{~min})$. According to Molchanov et al. [2004, 2006], these frequencies correspond to the frequencies of the turbulence induced in the ionosphere by the LAIC coupling process during the earthquake preparation period. It is also indicated that, remarkably, components with frequencies approaching the tidal frequencies are also present. This is also indicated in the power spectrum of TEC variations over the MATE station around the day of the main shock, which is shown as an example in Figure 9.

These observations have also been seen in the past on the occasions of other earthquakes [Contadakis et al. 2007, 2008], and they have an observational counterpart in

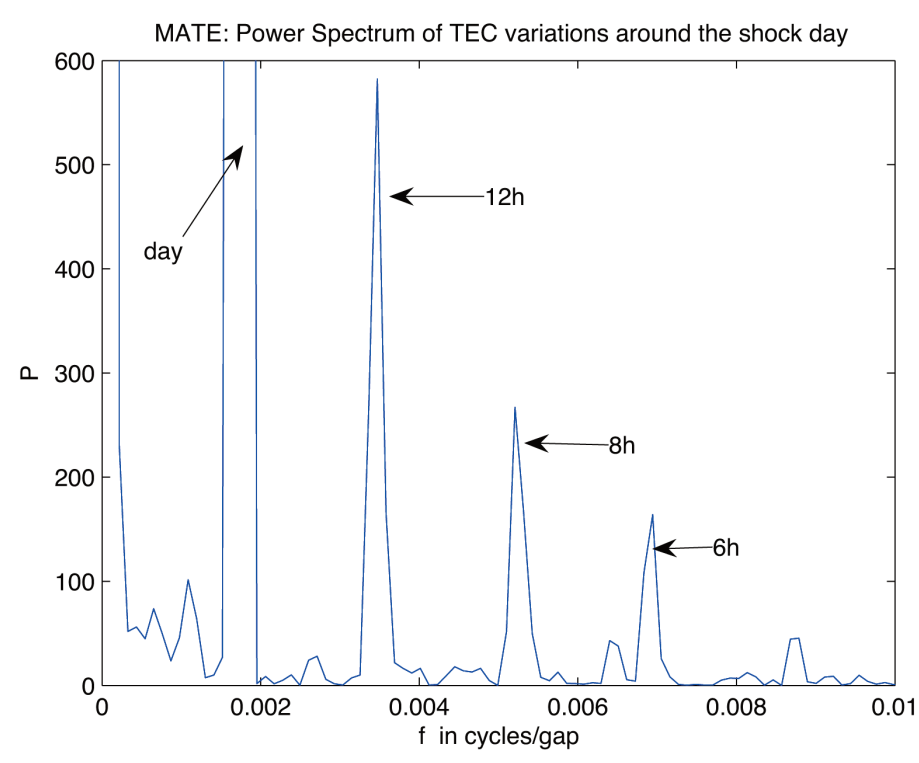

Figure 9. Power spectrum of TEC variations over the MATE station around the day of the main shock, April 6, 2009.

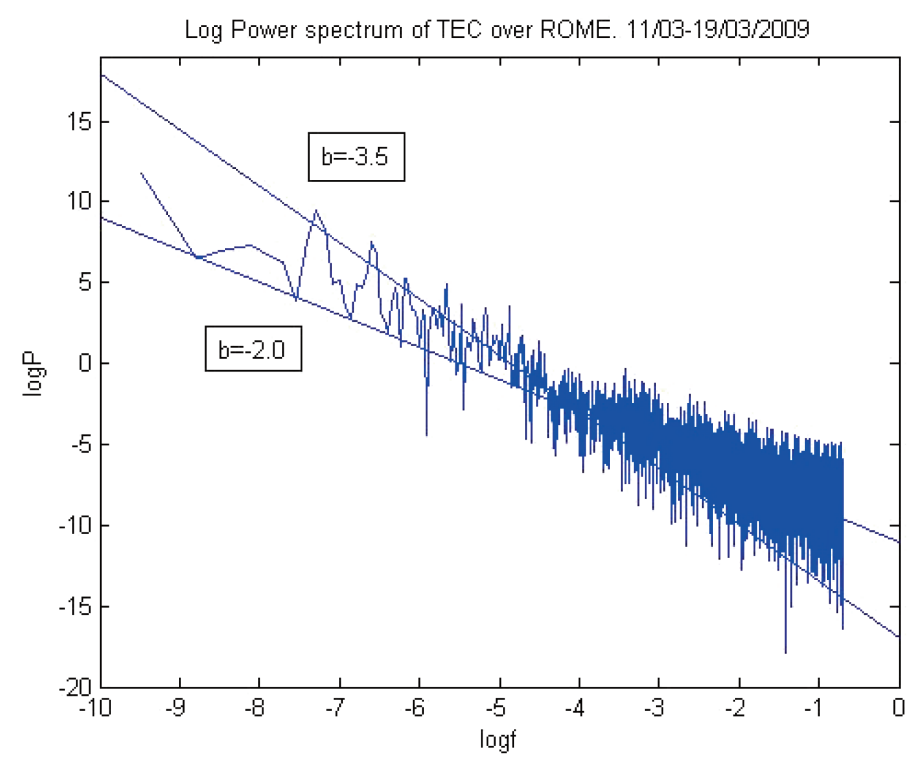

Figure 10. Logarithmic power spectrum of TEC over Rome in the time interval of March 11, 2009 to March 19, 2009. 
atmospheric tides exalting [Arabelos et al. 2004, 2008], as well as in tidal frequency exalting of the VLF/LF radio transmissions [Biagi et al. 2003].

\subsection{Fast Fourier transform analysis}

The power spectra of the TEC variations provide information on their frequency content. Apart from the well-known and well-expressed tidal variations, for which the reliability of their identification can be easily inferred by statistical tests, small amplitude space-temporal transient variations cannot be reliably identified through any statistical test. Nevertheless, looking at the logarithmic power spectrum, we can determine from the slop of the diagram whether the variations that contribute to the spectrum are random or periodic. If they are random, the slop will be 0 , which corresponds to white noise, or -2 , which correspond to the Brownian walk; otherwise the slop will be different [Turcotte 1997]. This means that we can trace the presence of periodic variations in the logarithmic power spectrum of TEC. This method was successfully applied in a previous study [Contadakis et al. 2008]. As an example, Figure 10 shows the logarithmic power spectrum of TEC over Rome in the time interval between March 11, 2009, and March 19, 2009. It can be seen that the spectrum of TEC variations over Rome contain random variations in the high frequency part ( $\mathrm{f}>0.0003 \mathrm{~Hz}$, period $<54 \mathrm{~min}$ ) and periodic variations in the low frequency part $(f<0.0003 \mathrm{~Hz}$, period $>54 \mathrm{~min})$.

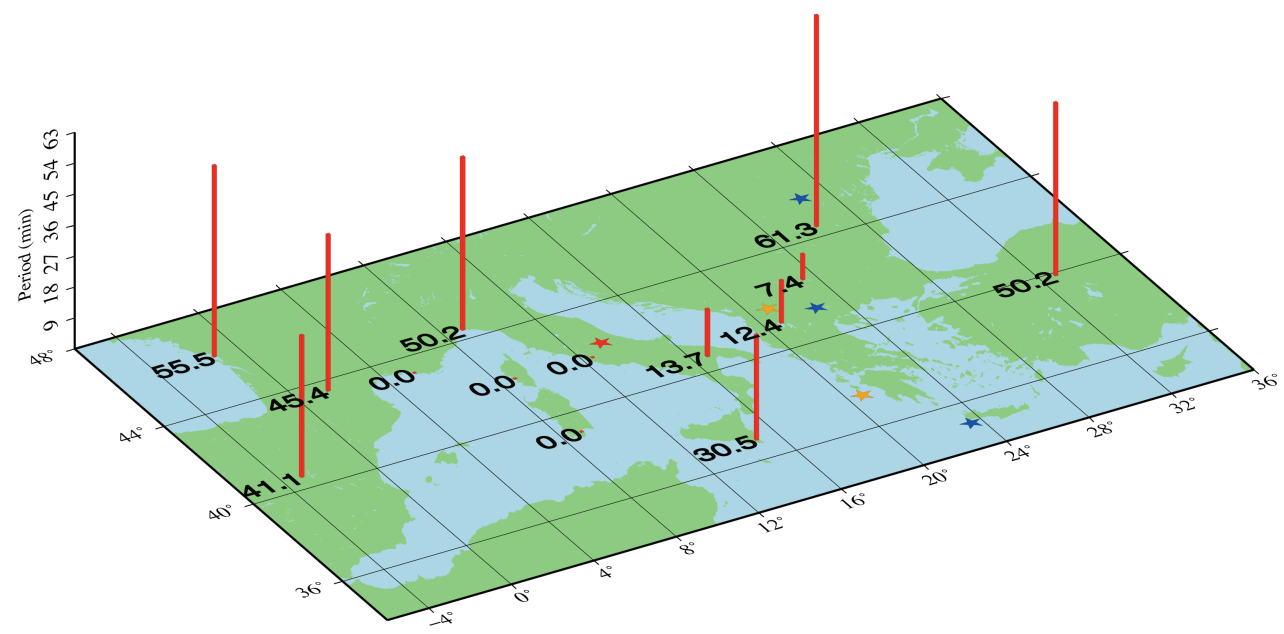

Figure 11. Distribution of the limited frequencies of TEC variations over the area of southern Europe for the co-seismic perturbation for April 6, 2009. ( $\star=$ the L'Aquila earthquake; $\star=$ earthquakes before the L'Aquila earthquake; $\star=$ earthquakes after the L'Aquila earthquake).

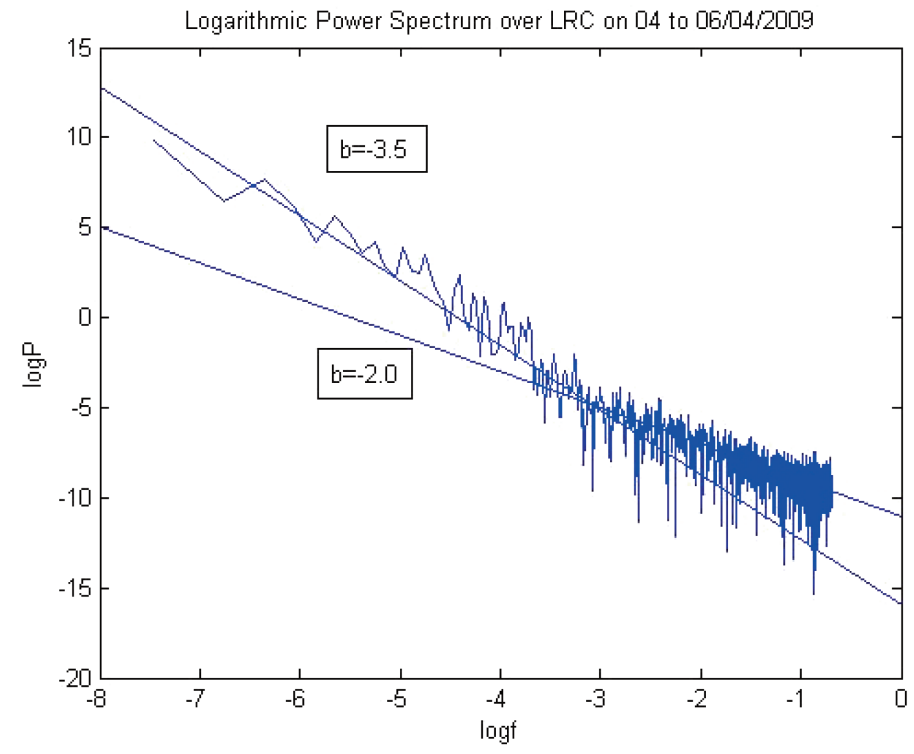

Figure 12. Logarithmic power spectrum of TEC over the LRC station on April 6, 2009. Limited frequency.

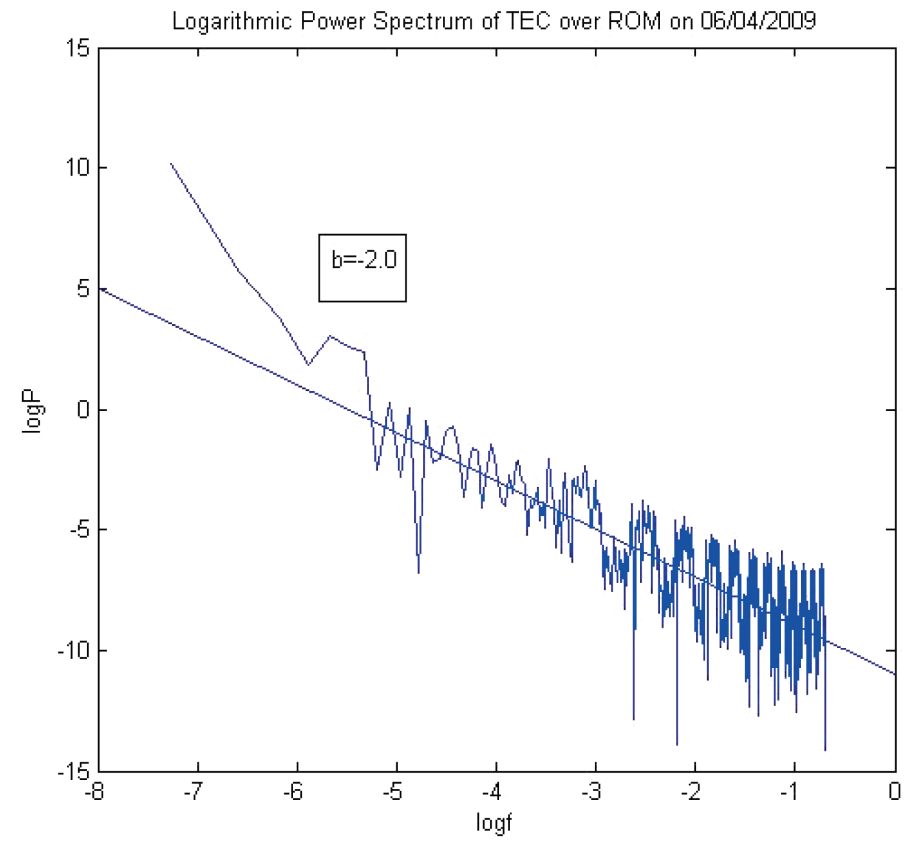

Figure 13. Logarithmic power spectrum of TEC over the Rome station on April 6, 2009. 
This is a typical logarithmic power spectrum of TEC, and we have seen that we can trace the presence of periodic variations. The breaking point in Figure 10 indicates the limited frequency below which (or correspondingly, the limited period above which) there are periodic variations of TEC.

Table 4 gives the distributions of the limited frequencies of TEC variations over the area of southern Europe for the co-seismic perturbation (April 4, 2009, to April 6, 2009). Figure 11 shows the corresponding distributions.

The limited period of TEC variations becomes smaller and smaller as we approach the earthquake epicenter, and becomes zero over the nearest stations. This means that the frequency content of TEC variations is extended to shorter wavelengths as we approach the epicenter, and near the epicenter no periodic components are seen. This is shown in Figures 12 and 13, with a comparison of the logarithmic power spectrum of TEC variations over La Rochel, a remote station, and over Rome, for the time of the L'Aquila earthquake. A qualitative explanation of this phenomenology can be offered on the basis of the LAIC model, which we used to explain the morning/ evening extensions of day-time TEC values and the observed frequencies of TEC variations during the time interval from March 29, 2009, to April 9, 2009. The tectonic activity during the earthquake preparation period produces anomalies at ground level that propagate upwards in the troposphere as acoustic waves or standing gravity waves. These acoustic or gravity waves affect the turbidity of the lower ionosphere, where sporadic Es layers can also appear, and the turbidity of the F layer, where complete disorganization of the gravity waves at the point of the arrival of the standing wave occurred. Therefore, the logarithmic power spectrum of TEC variations shows a random pattern over all of the frequencies. Subsequently, the disturbance produced starts to propagate in the ionospheres waveguide as the gravity wave and the inherent frequencies

\begin{tabular}{|c|c|c|c|c|}
\hline No & GPS station & $\begin{array}{l}\text { Frequency } \\
\qquad(\mathrm{Hz})\end{array}$ & $\begin{array}{c}\text { Period } \\
(\min )\end{array}$ & $\begin{array}{c}\text { Date (time) } \\
(\mathrm{dd} / \mathrm{mm} ; \mathrm{hh}: \mathrm{mm})\end{array}$ \\
\hline 1 & YEBES & 0.00040540 & 41.1116 & $04-06 / 04$ \\
\hline 2 & LRC & 0.00030033 & 55.4949 & $06 / 04$ \\
\hline 3 & TLSE & 0.00036682 & 45.4354 & $04-06 / 04$ \\
\hline 4 & MARS & inf & 0.0000 & $04-06 / 04$ \\
\hline \multirow[t]{4}{*}{5} & AJAC & 0.00183670 & 9.0745 & $04 / 04(00.00-11.03)$ \\
\hline & AJAC & 0.01109600 & 1.5021 & $04 / 04(11.07-13.00)$ \\
\hline & AJAC & 0.00302810 & 5.5039 & $04 / 04(13.01-24.00)$ \\
\hline & AJAC & $\inf$ & 0.0000 & $05-06 / 04$ \\
\hline 6 & GEN & 0.00033191 & 50.2138 & 04-06/04 \\
\hline \multirow[t]{5}{*}{7} & CAGL & 0.00061052 & 27.2991 & $04 / 04(00.00-14.44)$ \\
\hline & CAGL & 0.00050329 & 33.1155 & $04 / 04(14.45)-05 / 04(21.50)$ \\
\hline & CAGL & Inf & 0.0000 & $05 / 04(21.51)-06 / 04(08.35)$ \\
\hline & CAGL & 0.0023000 & 7.3891 & $06 / 04(08.36-16.35)$ \\
\hline & CAGL & 0.0014000 & 12.2663 & $06 / 04(16.37-24.00)$ \\
\hline 8 & ROM & inf & 0.0000 & $04-06 / 04$ \\
\hline 9 & NOT1 & 0.00054723 & 30.4562 & $04-06 / 04$ \\
\hline \multirow[t]{3}{*}{10} & MATE & 0.00121790 & 13.6850 & $04 / 04$ \\
\hline & MATE & 0.00134600 & 12.3830 & $05 / 04$ \\
\hline & MATE & 0.00090224 & 18.4730 & $06 / 04$ \\
\hline \multirow[t]{4}{*}{11} & OHRI & 0.00134600 & 12.3826 & $04 / 04$ \\
\hline & OHRI & 0.00020351 & 81.8972 & $05 / 04(00.00-13.21)$ \\
\hline & OHRI & 0.00151200 & 11.0232 & $05 / 04(14.00-24.00)$ \\
\hline & OHRI & 0.00073869 & 22.5625 & $06 / 04$ \\
\hline \multirow[t]{3}{*}{12} & SOFI & 0.00225560 & 7.3891 & $04 / 04(00.00-08.00)$ \\
\hline & SOFI & 0.00152240 & 10.9479 & $04 / 04(08.17-24.00)$ \\
\hline & SOFI & 0.00033191 & 50.2138 & $05-06 / 04$ \\
\hline 13 & BUCU & 0.00027175 & 61.3310 & $04-06 / 04$ \\
\hline 14 & ANKR & 0.00033191 & 50.2138 & 04-06/04 \\
\hline
\end{tabular}

Table 4. Limited frequency (period) of TEC variations over the network from April 4 to 6, 2009 
of the acoustic or gravity waves can be traced on TEC variations (i.e. the frequencies between $0.003 \mathrm{~Hz}$ [period, 5 $\min$ ] and $0.0002 \mathrm{~Hz}$ - period, $100 \mathrm{~min}$ ). According to Molchanov et al. [2004, 2006], these correspond to the frequencies of the turbulence induced by the LAIC coupling process to the ionosphere. As we move further from the disturbed point, in time or in space, the shorter wavelength variations are progressively attenuated, which is clear from the data given in Table 4.

\section{Concluding remarks}

The surveillance of TEC variations over southern Europe in the last month before the L'Aquila earthquake and the subsequent analysis have indicated that TEC oscillations over a broad range of frequencies occurred randomly over a broad area of several hundred kilometers from the earthquake. Morning and evening extensions of day-time TEC values were seen over all of the EUREF stations of this program, before, during, and after the main earthquake period; i.e. from March 29,2009 , to April 9, 2009. High frequency oscillations ( $\mathrm{f} \geq$ $0.0003 \mathrm{~Hz}$, period $\mathrm{T} \leq 60 \mathrm{~min}$ ) appear to indicate the location of the earthquake, although with questionable accuracy. However, the fractal characteristics of the frequency distribution indicates the locus of the earthquake with a relatively greater accuracy. We conclude that through acoustic or gravity waves, the LAIC mechanism can be used to explain this phenomenology.

Acknowledgements. The authors are grateful to Dr. Ciraolo (IFACCNR, Italy) for the provision of the TEC data for Rome, Italy, and to Prof. F. Arikan and Prof. U. Sezer, who are in charge of IONOLAB, for their willingness to provide useful information regarding the data of IONOLAB.

\section{References}

Afraimovich, E.L., N.P. Perevalova, A.V. Plotnikov and A.M. Uralov (2001). The shock acoustic waves generated by the earthquakes, Ann. Geophys., 19, 395-409.

Afraimovich, E.L., N.P. Perevalova and S.V. Voyeikov (2002). Traveling wave packets of total electron content disturbances from global GPS network data, LANL eprint archive, http://ru.arxiv.org/abs/physics/ 0211046.

Alperovich, L., V. Zheludev and M. Hayakawa (2003). Use of wavelet analysis for detection of seismogenic ULF emission, Radio Sci., 38, 1093; doi: 10.1029/2002RS002687.

Arabelos, D.N., G. Asteriadis, A. Bloutsos, M.E. Contadakis and S.D. Spatalas (2004). Atmospheric tide disturbances as earthquake precursory phenomena, Nat. Hazards Earth Syst., 4, 1-7.

Arabelos, D.N., G. Asteriadis, A. Bloutsos, M.E. Contadakis and S.D. Spatalas (2008). Correlation between seismicity and barometric tidal exalting, Nat. Hazards Earth Sys., 8, 1129-1137.

Arikan, F., H. Nayir, U. Sezen and O. Arikan,O. (2008). Esti- mation of single station interfrequency receiver bias using GPS-TEC, Radio Sci., 43,1-13, RS4004.

Arikan, F., A. Yilmaz, O. Arikan, I. Sa Yin, M. Gurun and S.A. Yildirim (2009). Space Weather Activities of IONOLAB Group: TEC Mapi, Geophys. Res. Abstr., 11.

Atzori, S., I. Hustad, M. Chini, S. Salvi, C. Tolomei, C. Bignami, S. Stramondo, E. Trasatti, A. Antonioli and E. Boshi (2009). Finite fault inversion of DInSAR coseismic displacement of the 2009 Aquila earthquake (Central Italy), Geophys. Res. Lett., 36, L15305; doi: 10.1029/2009GL039293.

Biagi, P.F., R. Piccolo, V. Capozzi, A. Ermini, S. Martellucci and C. Ballecci (2003). Exalting in atmospheric tides as earthquake precursors, Nat. Hazards Earth Sys., 3(3/4), 197-201.

Biagi, P.F., L. Castellana, T. Maggipinto, D. Loiacono, L. Sciavulli, T. Ligonzo, M. Fiore, E. Suciu and A. Ermini (2009). A pre seismic radio anomaly revealed in the area where the Abruzzo earthquake $(M=6.3)$ occurred on 6 April 2009, Nat. Hazards Earh Sys., 9, 1551-1556.

Cirella, A., A. Piatanesi, M. Cocco, E. Tinti, L. Scognamiglio, A. Michelini, A. Lomax and E. Boschi (2009). Rapture history of the 2009 L'Aquila (Italy) earthquake from non-linear joint inversion of strong motion and GPS data, Geophys. Res. Lett., 36, L19304; doi: 10.1029/2009GL039795.

Contadakis, M.E., D.N. Arabelos, G. Asteriadis, S.D. Spatalas and C. Pikridas (2007). TEC variations over the Mediteranean during the seismic activity period of 20th October, in the area of eastern Aegean., Geophys. Res. Abstr., 9.

Contadakis, M.E., D.N. Arabelos, G. Asteriadis, S.D. Spatalas and C. Pikridas (2008). TEC variations over the Mediteranean during the seismic activity period of the last quarter of 2005 in the area of Greece, Nat. Hazards Earth Sys., 8, 1267-1276.

Hayakawa, O., O.A. Molchanov, T. Kodama, V.V. Afonin and O.A. Akentieva (2000). Plasma density variations observed on a satellite possibly related to seismicity, Adv. Space Res. Lab., 26 (8), 1277-1280.

Hayakawa, M. (2007). VLF/LF radio sounding of ionospheric perturbations associated with earthquakes, Sensors, vol. 7, 1141-1158.

Hayakawa, M., Y. Kasahara, T. Nakamura, Y. Hobara, A. Rozhnoi, M. Solovieva, O.A. Molchanov and V. Korepanov (2011). Atmospheric gravity waves as a possible candidate for seismo-ionospheric perturbations, J. Atmos. Electr., 31 (2), 129-140.

Korepanov, V., M. Hayakawa, Y. Yampolski and G. Lizunov (2009). AGW as a seismo-ionospheric responsible agent, Phys. Chem. Earth, 34 (6-7), 485-495.

Liperovsky, V.A., C.-V. Meister, E.V. Liperovskaya, N.E. Vasileva and O. Alimov (2005). On Es-spread effects in the 
ionosphere before earthquakes, Nat. Hazards Earth Sys., 5 (1), 59-62.

Lisi, M., C. Filizzola, N. Genzano, C.S.L. Grimaldi, T. Lacava, F. Marchese, G. Mazzeo, N. Pergola and V. Tramutoli (2010). A study on the Abruzzo 6 April 2009 earthquake by applying the RST approach to 15 years of AVHRR TIR observations, Nat. Hazards Earth Sys., 10, 395-406.

Misiti, M., Y. Misiti, G. Oppenheim and J.M. Poggi (1996). Wavelet Toolbox, the Math Works Inc.

Molchanov, O., B.F. Biagi, M. Hayakawa, A. Lutikov, S. Yunga, D. Iudin, S. Andreevsky, A. Rozhnoi, V. Surkov, V. Chebrov, E. Gordeev, A. Schekotov and E. Fedorov (2004). Lithosphere-atmosphere-ionosphere coupling as governing mechanism for preseismic short-term events in atmosphere and ionosphere, Nat. Hazards Earth Sys., 4 (5/6), 757-767.

Molchanov, O., A. Schekotov, M. Solovieva, E. Fedorov, V. Gladyshev, E. Gordeev, V. Chebrov, D. Saltykov, V.I. Sinit$\sin$, K. Hattori and M. Hayakawa (2005). Near seismic effects in ULF fields and seismo-acoustic emission: statistics and explanation, Nat. Hazards Earth Sys., 5, 1-10.

Molchanov, O., A. Rozhnoi, M. Solovievna, O. Akentieva, J.J. Berthelier, M. Parrot, F. Lefeuvre, P.F., Biagi, L. Castellana and M. Hayakawa (2006). Global diagnostics of the ionospheric perturbations related to the seismic activity using the VLF radio signals collected on the DEMETER satellite, Nat. Hazard Earth Sys., 6, 745-753.

Molchanov, O.A. and M. Hayakawa (2008). Seismo Electromagnetics and Related Phenomena: History and latest results, TERRAPUB, Tokyo, $189 \mathrm{p}$.

Muto, M., T. Yoshida, M. Horie, M. Hayakawa, M. Parrot and O.A. Molchanov (2008). Detection of ionospheric perturbations associated with Japanese earthquakes on the basis of reception of LF transmitter signals on the satellite DEMETER, Nat. Hazards Earth Sys., 8, 135141.

Parrot, M., J.J. Berthelier, J.P. Leberton, J.A. Sauvaud, O. Santolik and J. Blecki (2006). Examples of unusual ionospheric observations made by the DEMETER satellite over seismic regions, Phys. Chem. Earth, 31, 486-495.

Pergola, N., C. Aliano, I. Coviello, C.Filizzola, N. Genzano, T. Lacava, M. Lisi, G. Mazzeo and V. Tramutoli (2010). Using RST approach and EOS-MODIS radiances for monitoring seismically active regions: a study on the 6 April 2009 Abtuzzo earthquake, Nat. Hazards Earth Sys., 10, 239-249.

Rozhnoi, A., M.S. Solovieva, O.A., Molchanov and M. Hayakawa (2004). Middle latitude LF (40 kH) phase variations associated with earthquakes for quiet and disturbed geomagnetic conditions, Phys. Chem. Earth, 29, 589-598.

Rozhnoi, A., O. Molchanov, M. Solovieva, V. Gladyshev, O.
Akantieva, J.J. Berthelier, M. Parrot, F. Lefeuvre, M. Hayakawa, L. Castellana and P.F. Biagi (2007). Possible seismo-ionosphere perturbations revealed by VLF signals collected on ground and satellite, Nat. Hazards Earth Sys., 7, 617-624.

Rozhnoi, A., M. Solovieva, O. Molchanov, K. Schwingenschuh, M. Boudjada, P.F. Biagi, T. Maggipinto, L. Castellana, A. Ermini and M. Hayakawa (2009). Anomalies in VLF radio signals prior the Abruzzo earthquake $(M=6.3)$ on 6 April 2009, Nat. Hazards Earth Sys., 9, $1727-1732$.

Svets, A.V., M. Hayakawa, O.A. Molchanov and Y. Ando (2004). A study of ionospheric response to regional seismic activity by VLF radio sounding, Phys. Chem. Earth, 29, 627-637,.

Turcotte, D.L. (1997). Fractal and Chaos in Geology and Geophysics (2nd Ed.), Cambridge University Press, Cambridge, U.K.

Yoshida, M., T. Yamauchi, T. Horie and M. Hayakawa (2008). On the generation mechanism of terminator times in subionospheric VLF/LF propagation and its possible application to seismogenic effects, Nat. Hazards Earth Sys., 8, 129-134.

\footnotetext{
${ }^{\star}$ Corresponding author: Michael E. Contadakis, Aristotle University of Thessaloniki, Department of Geodesy and Surveying, Thessaloniki, Greece; email: kodadaki@eng.auth.gr.
}

(C) 2012 by the Istituto Nazionale di Geofisica e Vulcanologia. All rights reserved. 